Brouwers, E.P.M., Baar, A.L. van, Pop, V.J.M. Does the Edinburgh Postnatal Depression Scale measure anxiety? Journal of Psychosomatic Research: 2001, 51(5), 659-663

\begin{tabular}{|l|l|}
\hline $\begin{array}{l}\text { Postprint } \\
\text { Version }\end{array}$ & 1.0 \\
\hline Journal website & $\underline{\text { http://www.sciencedirect.com/science/article/pii/S0022399901002458 }}$ \\
\hline Pubmed link & $\underline{\text { http://www.ncbi.nlm.nih.gov/pubmed/11728506 }}$ \\
\hline DOI & $10.1016 /$ S0022-3999(01)00245-8 \\
\hline
\end{tabular}

This is a NIVEL certified Post Print, more info at http://www.nivel.eu

\title{
Does the Edinburgh Postnatal Depression Scale measure anxiety?
}

\author{
EVELIEN P.M BROUWERS ${ }^{A,}$, ANNELOES L VAN BAAR ${ }^{\mathrm{B}}$, VICTOR J.M POP ${ }^{\mathrm{C}}$ \\ a National Institute for Health Services Research (NIVEL), PO Box 1568, 3500 BN Utrecht, \\ Netherlands \\ ${ }^{b}$ Department of Neonatology AMC, University of Amsterdam, Amsterdam, Netherlands \\ ${ }^{\mathrm{c}}$ Department of Clinical Health Psychology, Tilburg University, Tilburg, Netherlands
}

\begin{abstract}
Objective: The existence of a separate anxiety and depression dimension within the Edinburgh Postnatal Depression Scale (EPDS) has been reported previously. However, the concurrent validity of this anxiety subscale was never evaluated. We investigated whether (1) this existence of an anxiety subscale could be confirmed and (2) it more highly correlated with other measures of anxiety than the total EPDS. Methods: The SCL-90-R, the EPDS, and the State-Trait Anxiety Inventory (STAI) were filled out by 197 pregnant women. A principal component analysis (PCA) was used for confirmation of the subscales and correlations were computed between the (subscales of the) EPDS and the other measures of anxiety. Results: The existence of an anxiety scale within the EPDS was confirmed. However, this subscale did not yield higher correlations with other measures of anxiety than did the total EPDS. Conclusion: Investigators using the EPDS to screen for depression should realise that the instrument does not exclusively measure depression. It seems that both anxiety symptoms and depressive symptoms are more accurately measured when using the total 10item EPDS than when using the subscales.
\end{abstract}

\section{INTRODUCTION}

The question whether anxiety and depressive disorders are clearly separate entities continues to be a controversial issue [1]. Clark and Watson [2] introduced the tripartite model of anxiety and depression, which is based on the assumption that anxiety and depression each have distinct features (physiological hyperarousal and anhedonia, respectively) but also share a common dimension, called general distress or negative affect. As was pointed out by Bieling et al. [3], ideally, a measure of anxiety should assess both the general factor (negative affect) as well as physiological arousal and should not measure anhedonia. Similarly, a measure of 
Brouwers, E.P.M., Baar, A.L. van, Pop, V.J.M. Does the Edinburgh Postnatal Depression Scale measure anxiety? Journal of Psychosomatic Research: 2001, 51(5), 659-663

depression should assess negative affect and anhedonia, not physiological hyperarousal.

It has been suggested that the Edinburgh Postnatal Depression Scale (EPDS) [4] also is a good screening instrument for anxiety [5], as high correlations have been found between scores on the State-Trait Anxiety Inventory (STAI) [6] and the EPDS [5], [7] and [8]. Cox et al. [4] imply that the EPDS is unidimensional. However, Pop et al. [9] found that there are separate anxiety and depression dimensions within the EPDS, a finding later confirmed in other work [8]. As they did not include any other instruments measuring anxiety, the concurrent validity of the anxiety subscale was not evaluated.

The aim of the present study is to investigate whether (1) the existence of the anxiety subscale within the EPDS could be confirmed and (2) if confirmed, whether this anxiety subscale more highly correlated with other measures of anxiety than the entire (10-item) EPDS or the depressive symptoms subscale.

\section{METHOD}

\section{Subjects}

Subjects were derived from a larger study on the effect of maternal thyroid hormone during early gestation on child development currently being carried out. Here, 1361 women were screened on thyroid function. Of all subjects with normal thyroid function, women with a low-normal amount of thyroid hormone were matched with women with higher thyroid hormone concentrations and invited for the follow-up study. Of these 278 women, 11 (4\%) did not want to participate in the follow-up study and 18 (6.5\%) were excluded according to exclusion criteria previously set for the larger study (fertility problems, gestational diabetes, gemelli, and rheumatoid arthritis). Furthermore, 52 (18.7\%) women were excluded because of missing data on the EPDS, STAI, or SCL-90 anxiety or depression subscales [10], resulting in a sample size of 197 women. Women in the follow-up study did not differ significantly from the 1361 women originally screened in educational level, marital status, or age. Except for one woman who was divorced and one who was single, all women were married or living together with their partner. Sample characteristics of the subjects in the follow-up study are shown in Table 1.

\section{[TABLE 1]}

\section{INSTRUMENTS}

Depressive symptoms were measured at 24 weeks of gestation by the EPDS and the depression subscale of the SCL-90. The EPDS (see Appendix A) is a 10-item selfreport scale designed as a screening instrument for postnatal depression but has also been validated in nonpostnatal women [11]. Each item is scored on a four-point scale (0-3), the minimum and maximum scores being 0 and 30, respectively. Scores are transformed so that higher scores indicate a higher intensity of depressive symptoms. The EPDS rates the intensity of depressive symptoms present within the previous 7 
Brouwers, E.P.M., Baar, A.L. van, Pop, V.J.M. Does the Edinburgh Postnatal Depression Scale measure anxiety? Journal of Psychosomatic Research: 2001, 51(5), 659-663

days (see Appendix A for a description of the items). A cut-off score of 12/13 has been found to identify most seriously depressed women, although in case of a score of 9 or more, clinical assessment has been recommended [12]. In 1992, the EPDS was translated into Dutch and was found to have good psychometric properties [9].

The SCL-90 [13], the Dutch version of the SCL-90-R [10], is a 90-item self-report scale measuring multidimensional psychopathology. It was filled out at 24 weeks of gestation. The SCL-90 contains eight subscales, of which only the anxiety subscale (10 items) and the depression subscale (16 items) were used in the present study. The (Dutch version of the) SCL-90 was found to have good psychometric qualities [14].

Finally, anxiety was also measured at 32 weeks of pregnancy by means of the STAI [6]. This self-report questionnaire consists of two subscales each containing 20 items. The state anxiety subscale measures transient anxiety or anxiety at the moment of scoring. State anxiety is conceptualised as a transient emotional condition of the individual, characterised by subjectively experienced feelings of tension, together with a heightened activity of the autonomous nervous system. Trait anxiety measures dispositional anxiety or anxiety in general. It refers to relatively stable individual differences in the tendency to react with a more intense state anxiety in situations that are perceived as threatening. Trait anxiety measures reflect anxiety proneness; differences between individuals in the probability that anxiety states will be manifested under circumstances involving varying degrees of stress. Higher scores on the STAI indicate a higher intensity of anxiety. The Dutch version of the STAI has been validated previously (Dutch version: Zelfbeoordelings Vragenlijst STAIDY) [15].

\section{STATISTICAL ANALYSIS}

Analyses were computed by means of SPSS. First, a principal component analysis (PCA) was computed to investigate if in the present sample an anxiety and a depressive subscale could be found. Cronbach's $\alpha$ 's were computed to investigate the reliability of the subscales and the total EPDS. Subsequently, Pearson correlations were computed between the (subscales of the) EPDS and the other measures of anxiety. As Bieling et al. [3] have argued that the trait anxiety subscale contains a depression subscale, correlations were also computed between the (subscales of the) EPDS and the STAI-A subscale (i.e. the original trait anxiety subscale minus the items measuring depressive symptoms according to Bieling et al.).

\section{RESULTS}

Mean scores and standard deviations of the total group on the scales are presented in Table 2. PCA with varimax rotation revealed three components with eigenvalues of $>1$. Of the first component, items $1,2,6,7,8$, and 9 had a factor loading higher than 0.40 . Of the second and third, these were items 3, 4, 5, 6 and 7, 8, 9, 10, respectively. Although item 8 loaded high on both the first and the third components, it loaded higher on the first, in which it was included. Items 6 , 7, and 9 did not discriminate adequately between components and were omitted from the final subscales found: a depressive symptoms subscale (items 1, 2, and 8) and an anxiety symptoms subscale 
(items 3, 4, and 5). Item 10 ("The thought of harming myself has occurred to me") was the only item in the third component that discriminated well from the other components. The third component was not included in the correlational analysis. Because item 10 clearly was different from the other items, it was verified if a PCA without this item would still yield an anxiety and a depressive symptoms subscale, which was confirmed. In the PCA with the 10 items, the "depressive symptoms" and "anxiety symptoms" subscales accounted for $39.9 \%$ and $12.2 \%$ of the total variance of the 10 items, respectively. Results are presented in Table 3. Cronbach's $\alpha$ for the total EPDS was found to be .80, for the depressive symptoms subscale .79, and for the anxiety subscale .60 (data not shown). Scores on the EPDS depressive and anxiety symptoms subscales were computed by summing scores on each item.

\section{[TABLE 2][TABLE 3]}

A Pearson correlation of .37 was found between the "anxiety symptoms" subscale and the "depressive symptoms" subscale ( $P<.001$, two-tailed). Subsequently, Pearson correlations were computed between the following subscales: the anxiety symptoms and depressive symptoms subscales of the EPDS, the total EPDS, the SCL-90 depression and anxiety subscales, the state and trait subscales of the STAI, and the STAI-A. All correlations were highly significant ( $P<.001$, two-tailed). As can be seen in Table 4, all correlations yielded similar results, although the highest correlations were found between the total EPDS and the SCL-90 and STAI measures.

\section{[TABLE 4]}

\section{DISCUSSION}

In the present study, the EPDS was found to contain an anxiety subscale and a depressive symptoms subscale. This finding corresponds with the work of others [8] and [9]. Items 6, 7, and 9 did not discriminate adequately between components and for this reason were left out of the subscales. With reference to the tripartite model of depression and anxiety, it may well be that these items measure general distress, a feature that depression and anxiety share. PCA also revealed a third component. However, the only item that discriminated well on this third component was item 10 ("The thought of harming myself has occurred to me"). This item has been criticised for not being suitable for antenatal use [16], as pregnant women may interpret this differently (e.g. "I am preoccupied by the thought of falling and hurting myself"). Moreover, in the present study, 192 (97.5\%) women indicated never to have had the thought of harming themselves. For these reasons, the third component was left out of further analyses.

Contrary to expectations, the anxiety symptoms subscale did not more highly correlate with other measures of anxiety than the depressive symptoms subscale or the total EPDS. In fact, it was found that using the total EPDS yielded slightly higher correlations than either subscale used separately. Several explanations can be given for the finding that the anxiety symptoms subscale did not more highly correlate with the other measures of anxiety than the total EPDS. First, based on the tripartite model 
of anxiety and depression, the ideal instrument for the assessment of anxiety should measure the feature that anxiety and depression share (i.e. negative affect) as well as physiological arousal, which is typical of anxiety. The three-item anxiety scale that was found in the EPDS does not contain any items specifically on hyperarousal. A second explanation may relate to the fact that anxiety is not a unitary construct [17]. Anxiety may be generalised or focused upon particular situations. It may refer to fear, worries, feelings of insecurity and incompetence, increased arousal, a sense of respiratory constriction, muscular tension, tremor and restlessness, and a variety of somatic discomforts based upon the overactivity of the autonomic nervous system. Keedwell and Snaith [17] argue that a problem with the attempted coverage of all aspects of anxiety in a single scale is that it is unusual for all aspects to be present to an equal degree in one individual. In addition, Kabacoff et al. [18] present the view that the diagnosis of a major depressive episode is a more discrete and circumscribed process than the diagnosis of an anxiety disorder. Hence, considering how difficult it is to measure anxiety accurately and reliably, a three-item anxiety subscale is likely to be insufficient.

Furthermore, it should be pointed out that in contrast to the other items, all three items on the anxiety symptoms subscale contained a subjective, negative judgement about the feelings (I have blamed myself unnecessarily when things went wrong; I have been anxious or worried for no good reason; I have felt scared or panicky for no very good reason). This element may refer to a third factor, for example, low selfesteem, which is not measured in the items of the "depressive symptoms" subscale in a similar way. This could obscure an accurate measurement of anxiety.

In the present study, moderately high correlations were found between the total EPDS measured at 6 months of gestation and the anxiety measures assessed 2 months later. Stuart et al. [5] found similar correlations between the EPDS and state and trait anxiety measured 4 months later. However, when the EPDS and state and trait anxiety were measured at the same time, they found correlations ranging from $r=.73$ to $r=.82$. Similarly, Green [8] found correlations between trait anxiety measured at 16 weeks of pregnancy and the EPDS 5 and 8 months later that were similar to those of the present study, whereas correlations of state anxiety and the EPDS measured at the same time were higher. Although methodologically it would have been preferable to measure the EPDS and the STAI at the same point in time, it is unlikely that this has affected the correlational differences between the subscales. Hence, although the correlations between the EPDS and the STAI would have been higher had they been measured at the same time, there is no reason to assume that the subscales of the EPDS would have had higher correlations with the other measures of anxiety and depression than the total EPDS.

An additional limitation of the study is that only self-report instruments were used and no syndromal diagnosis of anxiety was used as a golden standard to validate the anxiety symptoms scale. However, considering the STAI and SCL-90 have good psychometric properties, based on the present findings, it is not to be expected that the use of a clinical assessment would yield markedly different results. 
Brouwers, E.P.M., Baar, A.L. van, Pop, V.J.M. Does the Edinburgh Postnatal Depression Scale measure anxiety? Journal of Psychosomatic Research: 2001, 51(5), 659-663

In conclusion, the existence of an anxiety subscale and a depressive symptoms nivel subscale within the EPDS was confirmed. Investigators using the EPDS to screen for depression should realise that the instrument does not exclusively measure depression. It seems that both anxiety symptoms and depressive symptoms are more accurately measured when using the total 10-item EPDS than when using the subscales.

\section{APPENDix A.}

The EPDS [4]

1. I have been able to laugh and see the funny side of things.

2. I have looked forward with enjoyment to things.

3. I have blamed myself unnecessarily when things went wrong.

4. I have been anxious or worried for no good reason.

5. I have felt scared or panicky for no very good reason.

6. Things have been getting on top of me.

7. I have been so unhappy that I have had difficulty sleeping.

8. $\quad$ I have felt sad or miserable.

9. I have been so unhappy that I have been crying.

10. The thought of harming myself has occurred to me.

\section{REFERENCES}

[1] JM Gorman Comorbid depression and anxiety spectrum disorders

Depression Anxiety, 4 (1997), pp. 160-168

[2] LA Clark, D Watson Tripartite model of anxiety and depression: psychometric evidence and taxonomic implications J Abnorm Psychol, 100 (3) (1991), pp. 316-336

[3] PJ Bieling, MM Antony, RP Swinson The State-Trait Anxiety Inventory, trait version: structure and content re-examined Behav Res Ther, 36 (1998), pp. 777-788

[4] JL Cox, JM Holden, R Sagovsky Detection of postnatal depression: development of the 10-item Edinburgh Postnatal Depression Scale Br J Psychiatry, 150 (1987), pp. 782-786

[5] S Stuart, G Couser, K Schilder, MW O'Hara, L Gorman Postpartum anxiety and depression: onset and comorbidity in a community sample J Nerv Ment Dis, 186 (7) (1998), pp. 420-424

[6] CD Spielberger, RL Gorsuch, RE Lushene STAI manual for the State-Trait Anxiety InventoryConsulting Psychologists Press, Palo Alto, CA (1970)

[7] R Tamaki, M Murata, T Okano Risk factors for postpartum depression in Japan Psychiatr Clin Neurosci, 51 (1997), pp. 93-98

[8] JM Green Postnatal depression or perinatal dysphoria? Findings from a longitudinal community-based study using the Edinburgh Postnatal Depression Scale 
Brouwers, E.P.M., Baar, A.L. van, Pop, V.J.M. Does the Edinburgh Postnatal Depression Scale/ measure anxiety? Journal of Psychosomatic Research: 2001, 51(5), 659-663

J Reprod Infant Psychol, 16 (1998), pp. 143-155

[9] VJ Pop, IH Komproe, MJ Van Son Characteristics of the Edinburgh Post Natal

Depression Scale in The Netherlands J Affective Disord, 26 (1992), pp. 105-110

[10] LR Derogatis, PA Cleary Confirmation of the dimensional structure of the SCL-90: a study in construct validation J Clin Psychiatry, 33 (1977), pp. 981-989

[11] JL Cox, G Chapman, D Murray, P Jones Validation of the Edinburgh Postnatal Depression Scale (EPDS) in non-postnatal women J Affective Disord, 39 (1996), pp. 185189

[12] JL Cox, D Murray, G Chapman A controlled study of the onset, duration and prevalence of postnatal depression Br J Psychiatry, 163 (1993), pp. 27-31

[13] WA Arrindell, JHM Ettema SCL-90. Handleiding bij een multidimensionele psychopathologie-indicatorSwets \& Zeitlinger, Lisse (1981)

[14] L Meeuwesen, WA Arrindell, FJ Huyse Psychometrische kwaliteiten van de Symptom Checklist (SCL-90) bij poliklinische patiënten met buikpijn of lage rugklachten T Soc Gezondheidsz, 70 (1992), pp. 123-131

[15] HM Van der Ploeg, PB Defares, CD Spielberger Handleiding bij de ZelfBeoordelingsvragenlijst-Een nederlandstalige bewerking van de Spielberger State-Trait Anxiety InventorySwets \& Zeitlinger, Lisse (1980)

[16] JM Green EPDS by post Br J Psychiatry, 158 (1991), p. 865

[17] P Keedwell, RP Snaith What do anxiety scales measure? Acta Psychiatr Scand, 93 (1996), pp. 177-180

[18] RI Kabacoff, DL Segal, M Hersen, VB Van Hasselt Psychometric properties and diagnostic utility of the Beck Anxiety Inventory and the State-Trait Anxiety Inventory with older adult psychiatric outpatients J Anxiety Disord, 11 (1) (1997), pp. 33-47

\section{TABLES}

Table 1. Characteristics of the sample $(N=197)$

\begin{tabular}{|l||l|}
\hline Age & $30.8(3.2)$ \\
\hline \hline Mean (S.D.) & $21-39$ \\
\hline \hline Range & $82(41.6)$ \\
\hline Parity & $72(36.5)$ \\
\hline $0[n$ (\%)] & $43(21.9)$ \\
\hline $1[n$ (\%)] & $20(10.1)$ \\
\hline$\geq 2[n$ (\%)] & $122(61.9)$ \\
\hline \hline Educational level (highest qualification achieved) \\
\hline \hline 1. Lower education $[n(\%)]$ & $55(28.0)$ \\
\hline 2. Middle level $[n(\%)]$ & $26(13.2)$ \\
\hline 3. Higher education $[n(\%)]$ & $112(56.9)$ \\
\hline \hline Family income per year in Dutch guilders $(1$ Euro $=2.2$ guilders) \\
\hline \hline 1. Lower $(<50.000)[n(\%)]$ & $31(15.7)$ \\
\hline 2. Middle level (50.000-100.000) $[n(\%)]$ & $28(14.2)$ \\
\hline 3. Higher $(>100.000)[n(\%)]$ & $153(77.6)$ \\
\hline \hline 4. Unknown $[n(\%)]$
\end{tabular}


Table 2. Mean scores and standard deviations of the total group $(N=197)$

\begin{tabular}{|l||l||}
\hline & Mean (S.D.) \\
\hline \hline Depressive symptoms subscale (EPDS items 1, 2, and 8 ${ }^{\mathrm{a}}$ ) & $0.7(1.2)$ \\
\hline \hline Anxiety-related symptoms subscale (EPDS items 3, 4, and 5) & $2.8(1.8)$ \\
\hline \hline Total EPDS score (10 items) & $4.9(3.7)$ \\
\hline \hline Depression subscale of SCL-90 & $20.6(4.5)$ \\
\hline \hline Anxiety subscale of SCL-90 & $11.8(3.0)$ \\
\hline State anxiety (STAI) & $31.6(7.5)$ \\
\hline \hline Trait anxiety (STAI) & $30.0(6.6)$ \\
\hline
\end{tabular}

a. See Appendix A.

Table 3. PCA computed for the 10 items of the $\operatorname{EPDS}^{\mathrm{a}}(N=197)$

\begin{tabular}{|l||c||c|l||}
\hline $\begin{array}{c}\text { Item } \\
\text { no. }\end{array}$ & $\begin{array}{c}\text { Component 1 depressive } \\
\text { symptoms }\end{array}$ & $\begin{array}{c}\text { Component 2 anxiety } \\
\text { symptoms }\end{array}$ & $\begin{array}{c}\text { Component } \\
3\end{array}$ \\
\hline 1 & 0.87 & & \\
\hline 1 & 0.84 & & \\
\hline 3 & & 0.68 & \\
\hline 4 & & 0.73 & \\
\hline 5 & & 0.71 & 0.53 \\
\hline 6 & 0.52 & 0.56 & 0.43 \\
\hline 7 & 0.49 & & 0.45 \\
\hline 8 & 0.69 & & \\
\hline \hline 9 & 0.46 & & \\
\hline 10 & & & \\
\hline \hline
\end{tabular}

a. See Appendix A for details of items. For reasons of clarity, factor loadings under 0.40 are not presented. 
Table 4. Pearson correlations between (subscales of) the EPDS and subscales of the SCL-90 and the STAI $(N=197)$

\begin{tabular}{|c|c|c|c|c|c|}
\hline & $\begin{array}{c}\text { Depression } \\
\text { subscale of } \\
\text { SCL-90 } \\
\end{array}$ & \begin{tabular}{|c|} 
Anxiety \\
subscale of \\
SCL-90 \\
\end{tabular} & $\begin{array}{c}\text { State } \\
\text { anxiety } \\
\text { (STAI) } \\
\end{array}$ & $\begin{array}{c}\text { Trait } \\
\text { anxiety } \\
\text { (STAI) } \\
\end{array}$ & $\begin{array}{c}\text { STAI- } \\
\text { A [3] }\end{array}$ \\
\hline $\begin{array}{l}\text { Depressive } \\
\text { symptoms (EPDS } \\
\text { items } 1,2 \text {, and } 8^{\text {a }} \text { ) }\end{array}$ & .65 & .46 & .49 & .42 & .36 \\
\hline $\begin{array}{l}\text { Anxiety-related } \\
\text { symptoms (EPDS } \\
\text { items 3, 4, and 5 ) }\end{array}$ & .48 & .44 & .36 & .45 & .44 \\
\hline $\begin{array}{l}\text { Total EPDS (10 } \\
\text { items) }\end{array}$ & .68 & .56 & .54 & .54 & .49 \\
\hline
\end{tabular}

All correlations were significant on a $P<.001$ level.

a. See Appendix A. 